\title{
Didactic Situations and Didactical Engineering in university mathematics: cases from the study of Calculus and proof
}

\author{
Alejandro S. González-Martín ${ }^{\mathrm{a}^{*}}$, Isabelle Bloch ${ }^{\mathrm{b}}$, Viviane Durand-Guerrier ${ }^{\mathrm{c}}$, Michela \\ Maschietto $^{\mathrm{d}}$ \\ ${ }^{a}$ Département de Didactique, Université de Montréal, Canada; ${ }^{b}$ Laboratoire Culture, \\ Éducation, Société (LACES), University of Bordeaux, France; ' Institut de Mathématiques et de \\ Modélisation de Montpellier, Université Montpellier 2, France; ${ }^{d}$ Dipartimento di Educazione e \\ Scienze Umane, Università di Modena e Reggio Emilia, Italy
}

This paper discusses the use of the Theory of Didactic Situations (TDS) at university level, paying special attention to the constraints and specificities of its use at this level. We begin by presenting the origins and main tenets of this approach, and discuss how these tenets are used towards the design of Didactical Engineering (DE), particularly adapted at the tertiary level. We then illustrate the potency of the TDS-DE approach in three university level Research Cases, two related to Calculus, and one related to proof. These studies deploy constructs such as didactic contract, milieu, didactic variables, and epistemological analyses, among others, to design Situations at university level. We conclude with a few thoughts on how the TDS-DE approach relates to other approaches, most notably the Anthropological Theory of the Didactic.

Keywords: university mathematics education; Theory of Didactic Situations; Didactical Engineering; didactic contract; milieu

\section{The origins of the Theory of Didactic Situations (TDS)}

The origins of TDS date back to the late 1960s, when Brousseau started to think about the conditions that would ensure a rigorous construction of mathematical knowledge in a model of teaching and learning systems, as well as to determine the conditions of scientific observation of didactic activities (Brousseau, 2008). 


\section{A. S. González-Martín et al.}

To address these issues, Brousseau rejected the sole use of psychology (Warfield, 2006) for three main reasons: Piaget's work focused on individual children; constructivist approaches are insufficient for modelling the processes of mathematics learning in a satisfactory way - namely its social and cultural dimensions are not sufficiently taken into account (Artigue, 1999, p. 1378); and, these approaches do not fully articulate the relations between the didactic activity at stake and the mathematical content, the learning of which is being studied (Artigue, 2000). Taking into account these three reasons, the concept of Situation was defined as the ideal model of the system of relationships between students, a teacher ${ }^{1}$, and a mathematical milieu (see Core elements in the next section). We note that in what follows, as in Warfield (2006), we use Situation to refer to this theoretical construct - which allows predicting students' mathematical work under some conditions - and situation to refer to its actual implementation in a classroom.

The back and forth between the elaboration by researchers of mathematical Situations aiming to develop mathematical learning as the result of the students' work and ideas - and not as the result of imitating the teacher's actions - and the observations of experimental lessons, led to the foundation and refinement of a theory of mathematical situations (what would become TDS) and of didactical engineering (DE) (Brousseau, 2008, see also next section). Over the years, TDS has been refined continuously; in the next sections, we discuss how some of its core elements have been refined, especially concerning tertiary education.

TDS is a theory that analyses variables of teaching practice and explores their relationship with the production of mathematical knowing. We note that, as in Brousseau (1997), we use the term 'knowing' to refer to the French 'connaissance' (referring to an individual's knowledge), and 'knowledge' to refer to the French 'savoir' 
(referring to an institution's or a community’s knowledge). To foster mathematical learning and to ensure optimal learner autonomy, several desirable conditions were established (Brousseau, 2008, p. 249):

- The mathematical knowledge targeted by the problem should provide an optimal method of solving the problem.

- The text and the instructions of the problem should not make any reference to the targeted knowledge.

- It is acceptable that students may start working on the problem using inadequate strategies.

- Students can tell for themselves whether their attempt succeeded or failed.

- Without determining the solution, the verifications are suggestive.

- Amongst the empirically acceptable solutions, only one takes care of all the conditions of the problem.

- The solution can be found and tested by some students in a reasonable amount of time, and swiftly shared and verified by the others.

The main goal of this theory was to elaborate Situations satisfying as many of the previous conditions as possible for each piece of mathematical knowledge. Thus it is important to stress that the central object of TDS is not the cognising individual, but the Situation, which shapes and constrains the adaptive processes students can develop, and thus the mathematical knowing which can be constructed (Artigue, 2000, p.2).

The conditions above allow students to take an important part of the responsibility for producing their own knowing. However, especially at university level, these conditions have to be thoroughly adjusted, taking into account the targeted mathematical knowledge and the possible Situations associated with it, as well as the students’ previous knowledge, and adequate elements with which they can interact. In this sense, the teacher can play a more active role. We come back to this issue in the next section. 
A. S. González-Martín et al.

We now summarise the main tenets of TDS and then discuss some particularities of its use at university level, which we exemplify through three Research Cases.

\section{Main tenets of of the Theory of Didactic Situations (TDS) and didactical engineering (DE)}

Here we focus on those core TDS-DE notions that are essential to the three Research Cases we present in this paper. For detailed presentations of TDS in English, the reader can consult Brousseau (1997), Brousseau, Brousseau \& Warfield (2014), and Warfield (2006). The 2005 Educational Studies in Mathematics special issue is also a good reference for some of the more recent developments in TDS.

\section{Core elements of TDS}

TDS develops a set of conceptual tools that can be used towards constructing Situations which optimise the relationships between the mathematical activity of the teacher and of the students, in ways that maximise students' responsibility in this activity (Artigue, 1999, p.1378). A core TDS conceptual tool is Brousseau's notion of the didactic contract, the implicit set of expectations that teacher and students have of each other regarding mathematical knowledge and regarding the distribution of responsibilities during the teaching and learning processes. The notion of didactic contract is essential to design a Situation, but it has also been used to analyse ordinary (non-experimental) classroom practice (e.g. Hersant \& Perrin-Glorian, 2005).

As we said in the previous section, in TDS, the fundamental object is the notion of Situation, which is defined as the ideal model of the system of relationships between students, a teacher, and a milieu. Students' learning is seen as the result of interactions taking place within such systems, and is highly dependent on characteristics of these 
systems. A Situation is modelled according to two main levels: adidactic and didactic (Artigue, 2000).

The adidactic level concerns students' actions when engaged in the activity (fitting as many of the conditions identified in the previous section as possible), which involves interacting with a milieu (namely the set of material objects, knowledge available, and interactions with others, if any, that the learner has in the course of said activity). The learner's activity evolves within and against a milieu, which reacts to the student's actions, both in a collaborative and in an antagonistic way; the chain of actions and reactions supports the exploration of solving strategies and the production of some knowing. Depending on the interactions with the milieu, and the feedback and successive enrichments it provides (i.e., new knowledge, interactions), different phases of a Situation include (Artigue \& Houdement, 2007, p.366):

- action: knowing appears as means for action through models that can remain implicit,

- formulation: knowing develops through the building of an appropriate language,

- validation: knowing becomes part of a fully coherent body of knowledge.

The teacher's actions at the adidactic level can be modelled in terms of enrichment of the feedback provided by the milieu, in the cases where the feedback of the current milieu appears to be insufficient to ensure adidacticity, or in terms of adding new pieces of knowledge to it. For example, in the phase of validation, the tools used by the students may be inadequate, compelling the teacher to provide additional, auxiliary tools, such as symbols or rules that can be used towards proving within the mathematical theory at hand.

In the didactic level, the teacher offers the students the problem to solve, so they can 'own' it. This process, called devolution, makes the students enter the adidactic level. Once the students have produced some knowing to solve the given problem, 


\section{A. S. González-Martín et al.}

institutionalisation is the ultimate phase of a Situation, in which the teacher makes the necessary links with the aimed knowledge and provides the semiotic tools to present this knowledge, especially if these were not produced in the earlier phases. This phase was added to the three initially described because the student's construction of knowing is strongly attached to the context of the adidactic level, and several studies revealed that, at some point, the teacher had to intervene to maintain "a certain equilibrium between what is known, what can be expressed, what has been shown and what is agreed on as being known” (Brousseau, 2008, p. 252).

The concept of Situation emerged out of epistemological studies of the mathematical knowledge and experimentations with young students. These experimentations helped to define what a theoretical Situation is, fulfilling criteria of mathematical consistency and the existence of a milieu allowing students' actions, as well as the feedback from this milieu. They also led to analysis of how such a Situation can be implemented in class, with both cognitive and didactical purposes: to make students actors in the construction of knowledge and better organise the teaching of this knowledge. Thus, it is important to notice that TDS distinguishes between the theoretical Situation, as an ideal-type model, and its actual implementation in the classroom, which allows assessment of the students’ actual work about mathematics. Even if a Situation gives great importance to the construction of a milieu which fosters students’ adaptation and regulation processes (Artigue \& Perrin-Glorian, 1991, p.15), and maximising their autonomy, the possible mediations of the teacher are not neglected. This is the case even in the adidactic level, and varies with the complexity of the targeted mathematical knowledge. In this sense, and regarding the degree of learning autonomy, several studies elaborate further on this issue, acknowledging that rarely does the student have full responsibility for the construction of knowing, and showing 
that the actual development of a Situation in class will inevitably alternate phases where the student has more responsibility with phases where the teacher plays a more active role. These studies led to the introduction of the notion of Situations with an adidactic dimension (Bloch, 1999; Mercier, 1995) and to the study of the role of the teacher in them (Bloch, 1999; Margolinas, 2002).

Situations having a substantial adidactic dimension, giving the students a great amount of responsibility, and compatible with secondary and postsecondary curricula, are complex to build; a particularity is that the milieu at these levels usually comprises abstract mathematical signs, which are not yet seen by the students with their entire mathematical meaning. A key issue is then to identify collections of problems that allow substantial explorations of such meaning - Bloch (2003) offers examples of such Situations regarding the concept of function.

\section{Core elements of $\mathrm{DE}$}

The advantageous way of constructing and testing new Situations and their effectiveness in a controlled way was called didactical engineering (DE) (Brousseau, 2008). DE consists of designing, regulating and making controlled observations of experimental situations where certain mathematical knowledge appears as the optimal way to address a mathematical problem (Herbst \& Kilpatrick, 1999, p.7). It emerged and was consolidated as a research methodology in the early 1980s (Artigue, 1992; Artigue \& Perrin-Glorian, 1991) and became the dominant means for testing the validity of the theoretical assumptions of TDS (Artigue, 2000). DE was developed in order to take into systematic account the complexity of the systems a study wanted to investigate, in addition to proposing methodological ways of dealing with this complexity (Artigue, 2000). In this sense, the design of DE enables systematic 


\section{A. S. González-Martín et al.}

experimental research based both on TDS and the theory of didactic transposition; the former is situated more at a local level, modelling teaching situations so that they can be developed and managed in a controlled way, and the latter at a more global level, concentrating on the shifts from reference knowledge to knowledge to be taught (objects of teaching, as prescribed, for example in the curriculum), and then to the actual taught knowledge in class (Artigue, 1994).

The construction of DE begins with analyses of the epistemological (associated with the characteristics of knowledge), cognitive (associated with the characteristics of the learner), and didactical (associated with the characteristics of the educational system and the teaching) dimensions of the mathematical knowledge at stake. During this construction, researchers identify and act on a certain number of variables of the system, called didactic variables. These are defined as parameters of the Situation that influence the way students may solve a problem related to this mathematical knowledge. The teacher can set these parameters at a certain value, in order to achieve the desired learning outcome. The didactic variables determine the global (overall characteristics of the whole design) and local (specific to an activity) organisation of the DE. The a priori analyses try to determine how the choice of these variables can result in student behaviour that achieves the learning objectives, and they mainly focus on the adidactic component of the Situations. This choice aims to ensure that expected behaviours, if they appear, are a result of the knowledge the Situation aims to develop and of the possible interactions with the milieu. One of the essential points in the design entails a fine analysis of the students' conceptions, their difficulties and errors (cognitive dimension), and the DE is designed to produce, in a controlled way, the development of these conceptions (Artigue, 1992, p. 49). 
DE relies on TDS to implement Situations which aim to give students maximal responsibility in producing new mathematical objects and techniques which appear as optimal mathematical tools to the problems they are given. The three Research Cases in the following section illustrate, among other things, that this notion of maximal responsibility requires reconceptualisation at university level, due to the complex, abstract nature of the mathematics to be learnt. Our Cases also illustrate that in an epistemologically well-built Situation, where the values of the didactical variables are carefully chosen, students will be enabled to undertake efficient interaction with the milieu; and, that the teacher's mediations are instrumental in securing this efficiency. We precede our Research Cases with a brief overview of uses of TDS-DE in universitylevel studies.

\section{The use of TDS and DE at university level}

The level of abstraction and the complexity of the mathematics increase considerably in the transition between secondary school and university. TDS offers a potent tool for studies at these levels, since its epistemological dimension can ensure that some important aspects of the mathematical topics to be dealt with will be present in the design and implementation of activities. At least two characteristics of TDS are of relevance here, in two different but complementary ways:

- The notions of contract and milieu are suitable for analysis of students' work, both in ordinary mathematics courses and in experimental interventions, and for identification of what students have learned in terms of knowing;

- $\quad$ TDS is efficient in building new Situations based upon a strong epistemological analysis of the aimed knowledge, through DE (see for example Krysinska \& Schneider, 2002; Sackur \& Maurel, 2002). This analysis warrants that students will face 'real' 
A. S. González-Martín et al.

mathematical questions. They will have to answer these questions and have an authentic mathematical experience - make conjectures, experiment with heuristic solutions, and search for adequate means of reasoning.

In this sense, TDS acknowledges the particularities of postsecondary and university environments, and develops new questions and approaches that cater for these particularities. Among these particularities, Rogalski (1998) highlights:

(1) the complexity of the knowledge to teach, in particular its level of organisation and interrelations, the number of problems that can be tackled with this knowledge, and the need (not always explicit) of previous knowledge;

(2) the increasing amount of personal work from the students and the importance of personal initiative.

The use of TDS at university level started in the 1980s, and it has been used to work on a variety of mathematical topics (see also the 1998 Recherches en Didactique des Mathématiques special issue on postsecondary mathematics education).

One of the paradigmatic uses of TDS and construction of DE at university level is Artigue's work on differential equations (Artigue, 1994, 2000). The analyses of the epistemological, cognitive, and didactical dimensions of this topic allowed insight into why the current teaching of differential equations is dominated by direct solution and the use of the symbolic setting. Moreover, these analyses also allowed identification of a series of didactic variables that would guide the overall construction of a DE. One of these variables, suggested by the analysis of the epistemological dimension, was the use of the geometrical setting and the qualitative solution of differential equations, through the (also pioneering at the time) use of computers to produce plots of directional fields. The use of the geometrical setting is discussed, among others, in our first Research Case. 
Another paradigmatic example is the work developed around integrals, which helped to develop the principles of scientific debate (Legrand, 2001). In scientific debate at university, the didactic contract gives substantial responsibility to the students, who have to decide what is true and what is false in a claim. This brings the researchers face to face with institutional constraints and with the students' expectations about lecturing. The notion of integral has been the focus of more recent works that also develop epistemological analyses to construct DE, focusing for instance on the notion of area (Haddad, 2012) and infinite area (González-Martín, 2006), which we discuss in our second Research Case.

Some concepts of linear algebra have also been the focus of research which has stressed the role of historical analysis and the importance of the epistemological dimension (Dorier, 2000). In particular, the problems of complexity and abstraction are present in the domain of linear algebra, where some concepts have been labelled as FUGS (Robert, 1998), since they embody Formalisation, Unification, Generalisation, and Simplification. It seems that Situations involving these kinds of concepts are not easy to design, since they unify a wide variety of topics, and it is difficult to create Situations which stimulate the need for these concepts to emerge. In this sense, FUGS concepts have been recognised as a real conundrum for TDS. To tackle this conundrum, some researchers have added a semiotic perspective (e.g. Pierce’s in Bloch \& Gibel, 2011), with the purpose of being able to analyse the development of the students' mathematical repertoire. The combination of TDS with a semiotic perspective allows an analysis of how students use mathematical terms and construct formal proofs. An example of a Situation concerning proof is discussed in our third Research Case.

More recently, TDS has also been used to analyse the learning potential of online resources for university students. Cazes, Gueudet, Hersant \& Vandebrouck 


\section{A. S. González-Martín et al.}

(2006) studied the use of these resources, and in particular the changes they suppose in the didactic contract. They thus elaborated on the new responsibilities that appear for the students, and the possible conflicts that can emerge, and raised new questions about the use of online tutorials at university level, and about the processes of institutionalisation and reorganisation of knowledge when using these environments.

We now present three recent Research Cases (two on Calculus and one on proof) of university level application of TDS in order to zoom in more elaborately on some of the issues raised in this brief overview. We have translated all data in these Research Cases verbatim from French.

\section{Research Case 1: discover a transcendental number through a limit - a Situation about the fixed point of the cosine}

Our first Research Case presents a Situation aiming at presenting real numbers in their epistemological nature, and we discuss the main features of the milieu used, as well as the teacher's interventions. The Situation was trialled with first-year students in a university in Tunis. Before the experimentation, they had already studied the main theorems of convergence - and knew the basic elements of how to apply them to 'wellknown’ numerical and geometrical sequences - and continuity.

When they enter university, students generally have a weak conception of real numbers, and do not assign the right meaning to inscriptions such as $\sqrt{2}, \pi$ - for example, sometimes students say that $\pi$ is not a 'true' number, but just a 'sign' - or to symbols and parameters that are typically used in mathematical writing, seeing them as kinds of 'writings' (see Bloch, Chiocca, Job \& Schneider, 2007). However, at university, there is a conceptual 'jump', which requires working with general notations $(x, f \ldots)$ and no longer with specific numbers or functions. It is also necessary to shift from a vision 
of limits as 'the process of limit' to 'the existence of the mathematical object 'limit' with mathematical rules'. For these reasons, it seems reasonable that Situations about the concept of limit must include some work addressing the categories of numbers rational and irrational, including transcendental. In this sense, the 'nature' of the numbers plays the role of didactic variable of the Situation, simultaneously with the theorems needed.

The aim of the Situation presented in this example was to help students capture some links between real numbers and limits (every real number can be seen as the limit of a sequence of rational numbers). The students were asked to show, constructing its graph, that the function $y=\cos x$ has a fixed point and to prove its existence using some theorems. The concept of limit was thus chosen because it is usually the first analytic concept students meet. Other didactic choices taken into account in the Situation were:

- The use of graphs allows identification of mathematical objects whose existence is only formal; therefore it constitutes a rich milieu that allows grasping objects and conditions of the way objects operate, allowing students to notice that the fixed point of the cosine must exist, and also to visualise how fast different sequences converge to this number. To some extent, use of graphs can also provide valuable feedback - even if not formal since formal proofs will be needed eventually. However, the graphical milieu helps make formal proofs more convincing for the students.

- The Situation organises a logical access to the formalism of limits.

The Situation uses the cosine function, which is continuous on $[-1,1]$ and maps it into [1, 1]; thus, following the Fixed Point Theorem, it must have a fixed point (a point where the curve $y=\cos x$ intersects with the line $y=x$ ). Numerically, the fixed point is approximately $x=0.73908513321516$, but students are unlikely to have a spontaneous idea of this value, which is irrational (specifically, transcendental). Ghedamsi (2008) 


\section{A. S. González-Martín et al.}

trialled this Situation and, in order to link heuristic and formal work, organised it in three steps:

(1) A heuristic stage, using the graph, enabling a conjecture concerning the existence of a solution $\alpha$ to the equation $\cos x=x$, and efforts to find an approximation using a dichotomy ('halving') method. The Intermediate Value Theorem alerts the students to the fact that we can determine the existence of a number, without knowing its value. The teacher fosters a debate among the students to discuss whether these tools always enable them to find the 'exact' solution of an equation, and whether dichotomy methods are suitable for calculating approximations of numbers whose value is not known.

(2) An investigation with a first sequence, using some Calculus theorems (e.g., Fixed Point Theorem) to have a better idea of the value of $\alpha$ (Fig.1):

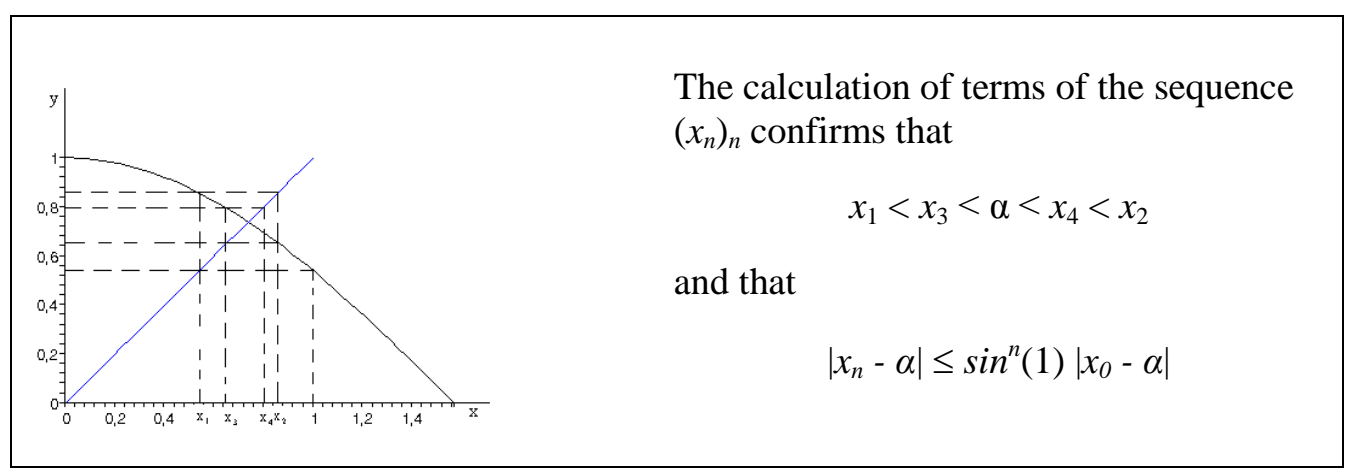

Figure 1. Estimations of the solution of $x=\cos x$.

Not 'finding' the number $\alpha$ surprised the students, who seemed to think that a number exists only if we can specify its exact value, as we remarked above. The interventions of the teacher are essential in choosing the appropriate formal tools, as the following interchange illustrates:

$\mathrm{S}_{1}: \quad u_{3}=\cos u_{2}$ and $u_{2}=\cos u_{1}$ and... we have to choose an $u_{0} \ldots$

$S_{2}: \quad u_{0}$ is in the interval $(0,1) \ldots$ 
$\mathrm{S}_{1}$ : but finally... it's the same! We cannot find the exact value?

$\mathrm{S}_{3}$ : not even with good software? As for [the number] $e$...

$\mathrm{S}_{2}$ : It means that the fixed point of the cosine has no exact value ... it exists because we find a sequence ...

Teach.: Is it the same with $\sqrt{2}$ ?

$\mathrm{S}_{3}: \quad \sqrt{2}$ has an exact value because its square is 2 .

Teach.: And what do we call a number like this $[\alpha]$ ? It is transcendental. And how do you think we could calculate this number?

$\mathrm{S}_{1}$ : We could use sub-sequences ... (students work with two sequences, one increasing and the other decreasing, both converging to $\alpha$ )

(3) Students realise that the method in (2) is not delivering results (the recursive sequence does not converge quickly), and use Newton's method to obtain a 'better' sequence to find the approximation. The teacher is again essential here to introduce this new method, and to help students interpret it with reference to the graph (using tangents).

The mediations of the teacher and the progression of the situation led to the conclusion that theoretical tools are needed to assure that a sequence has a limit. Finally, students were led to use theorems that they had seen previously, and that allowed them to speak of a number 'that cannot be seen'. These theorems allow the work on unknown objects, which have only a theoretical existence. In this way, students shift from assurance that a number exists, to knowing that we can approximate this number with as many decimal digits as desired, to knowing that the value of this number is the limit of a sequence. At the end of the work the students were able to enunciate the result:

If a sequence converges to a real number, then for whatever margin of error we accept, there exists a rank $n$ after which every term of the sequence is an approximation to this real number within this margin of error.

This work fosters an epistemological change in students' conceptions, allowing them to consider real numbers as conceptual objects in relation to other objects - i.e., limits - 


\section{A. S. González-Martín et al.}

within a mathematical theory. This work was designed to help students eventually to have access to the dialectic nature of these mathematical objects and to progress from seeing them as mere icons drawn by the teacher. In this Research Case we see that the mediations of the teacher become necessary at some point (particularly in step (3) of the Situation) to help the students reach the targeted mathematical knowledge; however, the Situation allows the students to engage in the phases of formulation and validation and have access to some knowing; and the feedback from the milieu allows 'seeing' sequences that seem to converge to $\alpha$. We observe that during such work, the function of the milieu is also to reassure students when they are in a phase of exploration: they must feel reassured that they are not undertaking an impossible venture. The values of the didactic variables, and the means available in the milieu, are chosen to guarantee this achievability. In this case, the principal tools of the milieu are graphs, calculations, and reasoning about the convergence - which is formerly established knowledge at this level of the students' studies. Institutionalisation of knowing about the epistemological nature of real numbers, and their link with the concept of limit, will then follow.

\section{Research Case 2: improper integrals as an extension of Riemann integrals}

Our second Research Case gives an overview of the importance of the epistemological work to construct a DE concerning improper integrals, and how this led to choosing some didactic variables. We focus on the first Situation of the DE and the main features of the milieu, as well as the importance of the teachers' mediations. The DE was implemented in the first year of a mathematics degree in Spain (González-Martín, 2006) and the students had already studied the theory about Riemann integrals and series. 
To define the Riemann integral of a function within an interval, two conditions are needed: for the interval to be closed and the function to be bounded within that interval; when one of these two conditions fails, an improper integral is defined as a generalisation of the Riemann integral. The analyses of the epistemological dimension of this topic (González-Martín \& Correia de Sá, 2008) showed that it appeared in the field as a generalisation of the calculation of areas (extended to infinite figures), mainly through geometrical considerations, and without aiming to establish a theory. However, the current teaching of improper integrals seems to ignore these aspects: improper integrals are usually introduced by developing a theory from the very beginning (with definitions and properties from the students' very first encounter with this concept ), not reinforcing its links with the Riemann integral, nor giving it meaning in terms of calculation of areas, but concentrating the teaching in the symbolic language, thereby ignoring geometrical considerations.

To propose a new way of teaching this concept at university, more coherent with its historical evolution, a DE was built (González-Martín \& Camacho, 2004) that aimed to introduce the new concept (improper integrals) building on what the students already knew (calculation of areas, Riemann integrals and series). The first Situation was constructed in order to make the students aware of the conditions needed to define the Riemann integral, since the new concept would be defined when one of these conditions fails. The milieu included a family of integrals (see Figure 2), asking the students to decide which of them are Riemann integrable:

\begin{tabular}{|l|l|l|}
\hline a) $\int_{1}^{10} \frac{1}{x} d x$ & b) $\int_{0}^{\pi} e^{x} d x$ & c) $\int_{1}^{\infty} e^{-x} d x$ \\
\hline d) $\int_{0}^{5} \frac{1+2 x}{x^{2}+1} d x$ & e) $\int_{0}^{1} \frac{1}{x} d x$ & f) $\int_{-1}^{3}[x] d x$ \\
\hline g) $\int_{-\pi}^{\pi} \sin x d x$ & h) $\int_{1}^{\infty} \frac{1}{x^{2}} d x$ & i) $\int_{-1}^{1} \frac{1}{x^{2}} d x$ \\
\hline
\end{tabular}




\begin{tabular}{|l|l|l|}
\hline j) $\int_{1}^{e} \ln x d x$ & k) $\int_{4}^{6} \frac{d x}{\sqrt{x^{2}-3 x-1}}$ & l) $\int_{0}^{10}(1+5 x)^{7} d x$ \\
\hline m) $\int_{1}^{\infty} x^{-1 / 3} d x$ & n) $\int_{-1}^{1}(1-|x|) d x$ & o) $\int_{0}^{1} f(x) d x$, with $f(x)=\left\{\begin{array}{l}1, \text { if } x \in[0,1] \cap(\mathfrak{R} \backslash Q) \\
0, \text { if } x \in[0,1] \cap Q\end{array}\right.$ \\
\hline
\end{tabular}

Figure 2. Integrals in the milieu of the first Situation about improper integrals.

The family of integrals was designed so that it covered the expected possible answers from the students. Their interactions with these examples would therefore allow them to identify the integrals which do not fill the necessary conditions for Riemann integrability. So, for example, it was expected from the a priori analyses that some students would believe that it is necessary for a function to be continuous to be integrable and the milieu included integral (f), which it is possible to calculate. Or, it was expected that students would think that it is necessary for the integrand to be differentiable, but the milieu included the integral (n), for which it is easy to see graphically that the integral is possible to calculate.

The interactions among the students and with the family of integrals in Figure 2 allowed them to identify the necessary conditions for defining the Riemann integral, and to realise that these conditions are necessary, but not sufficient (integral (o) had been studied previously by the students). However, the teacher’s mediations were also important, proposing strategies to the students on how to study these integrals systematically, and also suggesting the use of the graphic register to decide quickly about the Riemann integrability of some integrals ((f) and (n)), instead of proceeding through long calculations. This would also help settle one of the objectives of the DE: i.e., to give the graphic register some legitimacy among the students - a worthy objective considering that the epistemological analysis of the concept had shown a chronic underplay of geometrical considerations in the way the concept is typically taught. 
It was observed that the milieu designed helped the students to reflect on the conditions necessary to define the Riemann integral, making it clear which conditions are breached when defining the improper integral. This helped the students to conclude that the new concept would need the use of a limit (for instance,

$\left.\int_{a}^{\infty} f(x) d x=\lim _{b \rightarrow \infty} \int_{a}^{b} f(x) d x\right)$. However the teacher's intervention was needed to write this precisely, since the milieu did not provide the necessary symbolic tools. Also, the definition of locally integrable functions ${ }^{2}$ (which would be the only functions dealt with during the DE) was directly introduced by the teacher, since the milieu would not allow the students to construct such a definition, or to guess the type of functions that would be dealt with. The changes in the didactic contract also allowed going back and forth between moments with a stronger adidactic dimension, and moments of institutionalisation. This helped the students gradually to enter into this new way of working, and also helped the teacher encourage the students to accept the usefulness of the graphic register, especially in cases where this helped avoid long calculations.

\section{Research Case 3: using TDS to design and analyse situations of validation at university level}

Our third Research Case illustrates that TDS offers a fruitful theoretical framework to elaborate Situations aiming to engage students in processes of proof and proving. We discuss a Situation developed in France with undergraduate mathematics and engineering students and with graduate mathematics students in which the epistemological analyses led to choosing two proofs that allowed student discussion of the change of logical status of letters within the same proof.

Especially at university level, there is an increasing need for developing logical knowledge and competencies for fostering proof and proving, and research has revealed 


\section{A. S. González-Martín et al.}

some difficulties in manipulating existential, universal, and multiple quantifiers (Durand-Guerrier, Boero, Douek, Epp \& Tanguay, 2012), which are crucial at university. Such issues are the core of Barrier's work (2009), which focused on the phase of validation, showing the didactic relevance of adopting a semantic ${ }^{3}$ and dialogic ${ }^{4}$ perspective in the validation process in mathematics. In the experimental part of his research, Barrier selected two proofs in real analysis (one adapted from Liouville, the other adapted from Cauchy), and then analysed the quantification practices used by students when evaluating the validity of these proofs. In both cases, quantification is minimally present in the text of the proofs, while in the analysis of validity quantification issues intervene implicitly in a very subtle way, and so does the logical status of letters. We focus here on the proof adapted from Cauchy (Figure 3). 


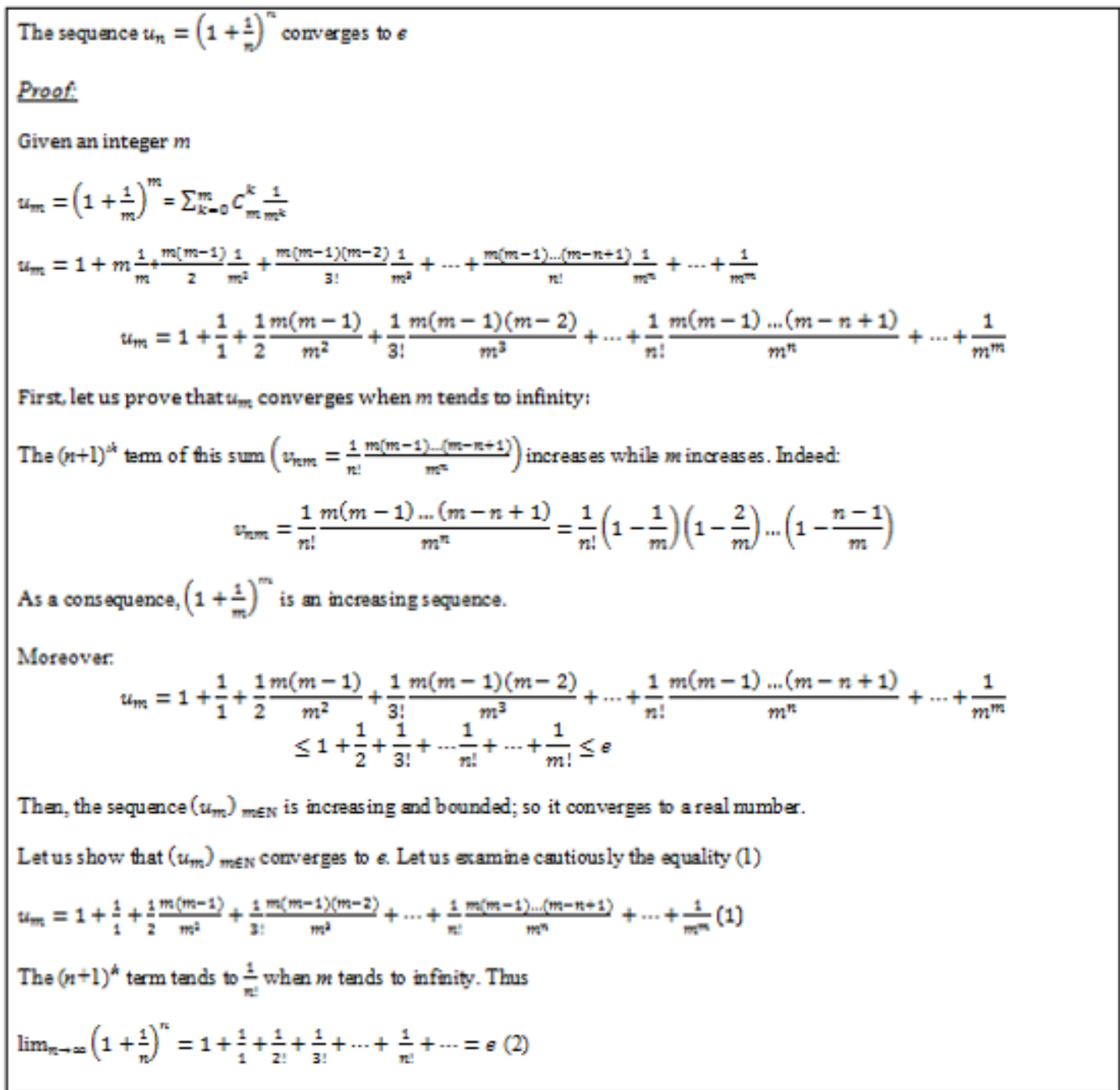

Figure 3. Proof by Cauchy given to the students (Barrier, 2009, p. 244).

In this proof, the step from (1) to (2) is invalid due to the use of the principle of substitution of infinitely small quantities in the limit of a sum. The mathematical contents of this proof had been previously studied in high school by the students participating in the experiment. For this reason, Barrier conjectured that this proof is a good candidate for triggering interaction between students, leading them to question quantification. In the language of TDS, Barrier hypothesised that the initial milieu of the phase of action (reading of the proof and studying its validity) had an adidactic potential $^{5}$. 


\section{A. S. González-Martín et al.}

The experiment was conducted in three different sessions: one with two groups of two or three first-year undergraduate students in mathematics; one with two groups of three high attaining graduate students in mathematics; and one with four groups of three or four first-year students from an Engineering school. Each group worked for about 40 minutes on one of the two proofs, and responded to the following:

(1) Determine and highlight each step of the proof.

(2) Analyse each step of the proof, saying whether it is possible to complete it and/or to propose a new formulation. Are all steps complete, rigorous, and valid?

(3) Is the proof valid?

Then, each group prepared a synthesis of their work to be presented to the other groups (if more than one group had worked on the same proof during the same session, all those groups prepared the synthesis together). The requirement for communication increased the social need to study the validity of the proof, and the preparation of the synthesis aimed to reactivate some debates or disagreements that were expected to appear during the analysis of the proof. These elements, together with the questions from the other students during the communication, contributed to enriching the milieu.

The data analyses were driven, among other considerations, by the following questions: Do the students identify the invalid steps in the proof? How do the students understand the use of letters in the proof?

Regarding Cauchy's proof, the first-year engineering students discussed neither the principle of substitution nor the validity of the proof. In contrast the first-year mathematics students discussed validity, and the graduates both discussed validity and amended the proof by correctly using the $\varepsilon-\eta$ quantification. All the groups working on this proof encountered difficulty with identifying the logical status of the letters. For example, the letter ' $n$ ' appears first in the proof with a status of mute letter in the sum 
defining the general term of the sequence $u_{m}$; then it appears as a variable implicitly, when defining the new sequence $v_{n, m}$, depending on the two variables $m$ and $n$. In each group, students considered the possibility of a 'variation of $n$ ' in the following sense: they wondered whether the row of the $n^{\text {th }}$ term of the sequence could move while $m$ increased, as in the following excerpt where three first-year mathematics students in the same group discuss the validity of the arguments used to establish that the sequence $u_{m}$ is increasing (pp. 297-298):

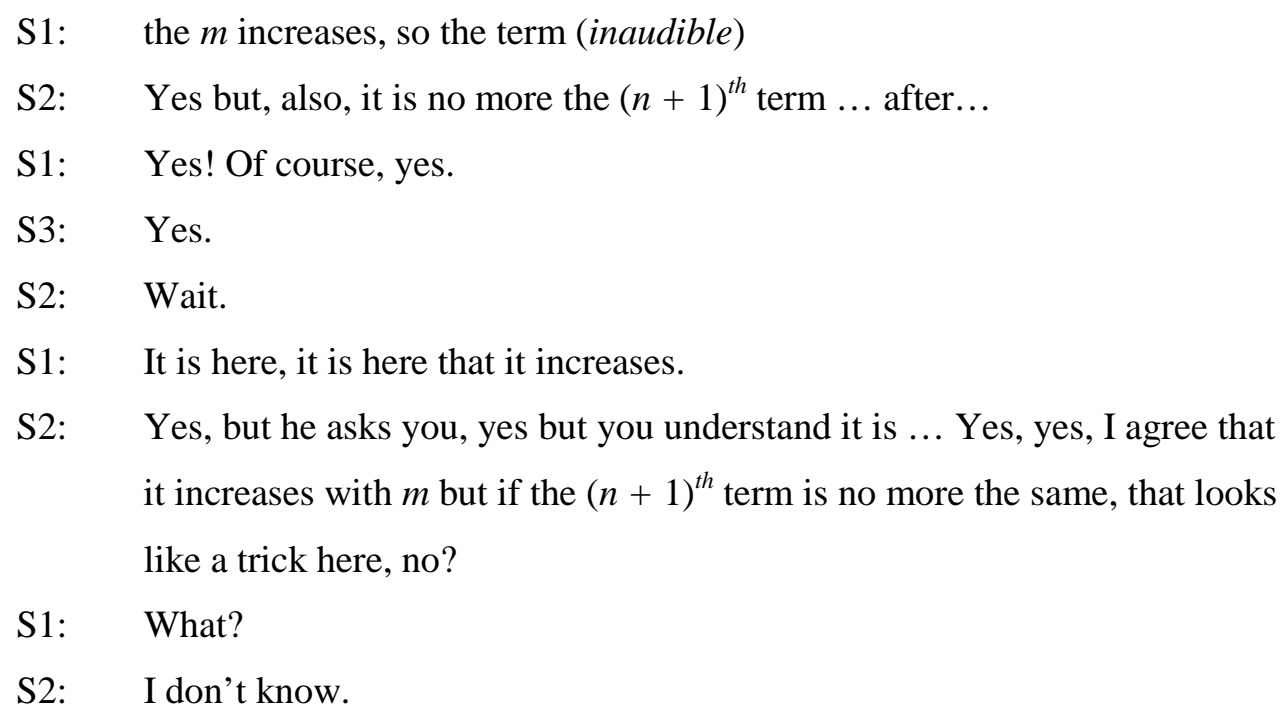

Barrier hypothesised that the co-occurrence of the two different logical statuses of the letter $n$ corresponds to heuristic interference leading students to consider dependence between $m$ and $n$, while in the sum $n$ is a mute letter. Relying on his data analyses, the author made the hypothesis that first-year students do not have the means to identify and deal with the numerous implicit elements that are present in the proofs presented in the experiment, which are not so distant from the proofs they experience in class. He also underlined the complexity and the subtlety of the logical issues in such proofs, in relation to the underlying mathematical difficulties.

Barrier's work emphasises the relevance of a semantic and dialogic perspective to design and analyse Situations - especially the phase of validation - particularly at 


\section{A. S. González-Martín et al.}

university level, and to recognise the role of logical issues in conceptualisation. The epistemological analyses were crucial in identifying proofs with the potential to make students more aware of the logical status of letters in proofs. These analyses, and the study of several historic proofs, also showed that the logical difficulties at stake in the two proofs have an epistemological consistency. Given the level of abstraction and subtlety of these issues, the role of the teacher becomes essential in helping students overcome their difficulties and fully grasp the subtleties they are confronted with.

\section{TDS and other frameworks at university level.}

Our three Research Cases illustrate the potential of TDS-DE to take into account the complexity of the mathematical knowledge taught at university, and the relevance of the epistemological analyses to design Situations that help students to grasp some of the subtleties of the mathematical knowledge at stake. These analyses also help to construct a milieu which fosters interactions among the students, and which also allows the teachers' interventions to enrich it.

The possibilities of combining TDS with other frameworks at university level have been explored since the 1980s by researchers such as Artigue (2000) and Legrand (2001), both cited earlier in this paper. Their works consider the construction of mathematical concepts through the interplay between different settings, as proposed by Douady (1986).

An important feature of TDS is that it focuses on the characteristics of the system formed by the teacher, the student, and the milieu, giving great importance to social interactions and to the regulations of the didactic contract that govern these interactions. TDS develops tools for observing and analysing the development of situations, and our Research Cases 1-3 illustrate its utility at university level in 
analysing Situations with an adidactic dimension. These tools also facilitate the analysis of ordinary teaching practice (Hersant \& Perrin-Glorian, 2005), even those planned in accordance with other theoretical approaches. In fact, given the specificities of teaching at university level, we contend that the analysis of ordinary lecturing at university can benefit from the combination of TDS with other approaches. Hersant and Perrin-Glorian (2005) compare TDS with other research on interaction, discussing how the notion of milieu can be compared to a "learning environment" (for example as in the work of Steinbring), or how the notion of didactic contract has similarities with the construct of “patterns of interaction” (p. 144). This particularity of TDS, the role of social interactions, is also discussed in Kidron, Lenfant, Bikner-Ahsbahs, Artigue \& Dreyfus (2008), where the issue of networking TDS with two other frameworks - the nested epistemic actions model for abstraction in context, and the theoretical approach of interest-dense situations - is developed. How social interactions are considered in the three approaches, and their complementarities, is discussed in depth, adding some comments to the ways each framework could complement the others. Finally, at university level, regarding the study of logic, TDS has been combined with Vergnaud's Theory of Conceptual Fields, which considers the important role of operative invariants, especially when interacting with natural logic (see Deloustal-Jorrand, 2004).

Furthermore, as we observed in this paper, TDS developed taking into account the notion of didactic transposition, which is central to Chevallard's (1998) work on the Anthropological Theory of the Didactic (ATD). As previously discussed, the development of DE at university needs to reconsider the issues related to didactic transposition, since the distance between academic knowledge and knowledge for teaching is smaller (especially in advanced mathematics courses, such as at Masters level); this issue was directly addressed in Serrano, Bosch \& Gascón (2010). TDS is 


\section{A. S. González-Martín et al.}

aware of the fact that learning happens in an institution, and the conditions that this fact may impose on learning. The notion of institution being central to ATD, it is not surprising that these two approaches have been combined to study learning and teaching. Job (2011) does so, for example, but at pre-university level, as do Artigue and Houdement (2007) who combined TDS and ATD to analyse the role of problem solving in the French curriculum and teaching practice. At university level, we find this combination, for instance, in the work of De Vleeschouwer (e.g. Winsløw, Barquero, De Vleeschouwer \& Hardy, 2014). The didactic contract is linked to an institution and, in particular at university level, the terms of the didactic contract can be quite strong. This issue can also be a source of networking of both theories, especially if we consider that issues related to transposition are clearly associated with those related to didactic contract in the transition from secondary to tertiary level institutions (see, for instance, Grønbæck, Misfeldt \& Winsløw, 2009). The connections of TDS with studies focusing on the distinction between 'knowledge to learn' and 'knowledge to teach', present in ATD, have also been discussed recently (Hersant \& Perrin-Glorian, 2005, p.145). Other recent combinations of both approaches can be found in the 2005 Educational Studies in Mathematics special issue.

The use of technologies has also been tackled using TDS, especially the construction of Situations in which the technology is a part of the milieu (e.g., Maschietto, 2008; Gueudet, Buteau, Mesa, \& Misfeldt, 2014), but also the changes the use of technologies or other resources produces in the didactic contract (e.g. Cazes et al., 2006). Other recent uses of TDS to analyse the use of technology, in this case studying the synergy between TDS and the Theory of Semiotic Mediation, have been shown in Maracci, Cazes, Vandebrouck \& Mariotti (2013). 
In any case, the possibilities of combining TDS with other approaches have already been explored in research, showing how different approaches can help to achieve better understanding of complex phenomena. These combinations have been further developed at the pre-university levels, but studies showing the possibilities of networking TDS with other approaches at university level seem promising as an approach to the complex phenomena, and some of the particularities, which take place at this level. We believe that such reflection about the particularities of university teaching and learning, as well as of the mathematical objects at play, may lead to further networking of TDS with other approaches, opening up new challenges for research.

\section{Notes}

\footnotetext{
${ }^{1}$ Throughout we use the term 'teacher' to designate the person whose role is to facilitate student learning. When the context concerns university level, the term refers to those who teach at university, acknowledging that this may correspond to different types of status: $\mathrm{PhD}$ students, lecturers, research associates, etc.

${ }^{2}$ Let $b \in \mathfrak{R}$ or $b=\infty$, and $f:[a, b) \rightarrow \mathfrak{R}$. $f$ is said to be locally integrable within $[a, b)$ if for every $x, a \leq x<b, f$ is Riemann-integrable in $[a, x]$.

3 'Semantic' refers here to the classical distinction in logic between syntax and semantics: semantics concerns the relation between signs and objects they refer to; syntax concerns the rules of integration of signs in a given system.

${ }^{4}$ To analyse an assertion in a dialogical way means placing it within the dialogue in which it takes place.

${ }^{5}$ For the complete a priori analysis, see Barrier (2009, pp.231-259).
} 


\section{References}

Artigue, M. (1992). Didactic Engineering. In R. Douady \& A. Mercier (Eds.), Research in Didactics of Mathematics (pp. 41-65). Grenoble: La Pensée Sauvage Éditions.

Artigue, M. (1994). Didactic engineering as a framework for the conception of teaching products. In R. Biehler, R.W. Scholz, R. Sträßer \& B. Winkelmann (Eds.), Didactics of Mathematics as a Scientific Discipline (pp. 27-39). Dordrecht: Kluwer Academic Publishers.

Artigue, M. (1999). The Teaching and Learning of Mathematics at the University Level. Crucial Questions for Contemporary Research in Education. Notices of the AMS, 46(3), 1377-1385.

Artigue, M. (2000). Didactic engineering and the complexity of learning processes in classroom situations. Communication to MADIF2. Gothembourg.

Artigue, M. \& Houdement, C. (2007). Problem solving in France: didactic and curricular perspectives. ZDM The International Journal on Mathematics Education, 39, 365-382.

Artigue, M. \& Perrin-Glorian, M.-J. (1991). Didactic Engineering, Research and Development Tool: some Theoretical Problems linked to this Duality. For the Learning of Mathematics, 11(1), 13-18.

Barrier, T. (2009). Une perspective sémantique et dialogique sur les situations de validation en mathématiques. Unpublished PhD Thesis. Université Lyon 1, France.

Bloch, I. (1999). L’articulation du travail mathématique du professeur et de l'élève dans l'enseignement de l'analyse en Première scientifique. Recherches en Didactique des Mathématiques, 19(2), 135-193.

Bloch, I. (2003). Teaching functions in a graphic milieu: What forms of knowledge enable students to conjecture and prove? Educational Studies in Mathematics, 52, 3-28.

Bloch, I., Chiocca, C.M., Job, P. \& Schneider, M. (2007). Du numérique aux limites : quelle forme prend la transition secondaire/supérieur dans le champ des nombres et de l'analyse ? Perspectives en Didactique des Mathématiques, Cédérom, IUFM d'Aquitaine. 
Bloch, I. \& Gibel, P. (2011). Un modèle d'analyse des raisonnements dans les situations didactiques : étude des niveaux de preuves dans une situation d'enseignement de la notion de limite. Recherches en Didactique des Mathématiques, 31(2), 191228.

Brousseau, G. (1997). Theory of Didactical Situations in Mathematics: Didactique des mathématiques, 1970-1990. Dordrecht: Kluwer Academic Publishers.

Brousseau, G. (2008). Research in mathematics education. In M. Niss (Ed.), Proceedings of the $10^{\text {th }}$ International Congress on Mathematical Education (pp. 244-254). IMFUFA: Denmark.

Brousseau, G., Brousseau, N. \& Warfield, V. (2014). Teaching Fractions through Situations: A Fundamental Experiment. Springer.

Cazes, C., Gueudet, G., Hersant, M. \& Vandebrouck, F. (2006). Using e-exercise bases in mathematics: case studies at university. International Journal of Computers for Mathematical Learning, 11, 327-350.

Chevallard, Y. (1998). Analyse des pratiques enseignantes et didactique des mathématiques: l’approche anthropologique. In R. Noirfalise (Ed.), Actes de l'Université d'Été de la Rochelle: Analyse des pratiques enseignantes et didactique des mathématiques (pp. 91-119). IREM de Clermont-Ferrand.

Deloustal-Jorrand, V. (2004). Studying the mathematical concept of implication through a problem on written proofs. In M. Johnsen Høines \& A. Berit Fuglestad (Eds.), Proceedings of the $28^{\text {th }}$ Conference of the International Group for the Psychology of Mathematics Education (vol.2, pp. 263-270),. Bergen, Norway: PME.

Dorier, J.-L. (Ed.) (2000). On the teaching of linear algebra. Dordrecht: Kluwer Academic Publishers.

Douady, R. (1986). Jeu de cadres et dialectique outil-objet. Recherches en Didactique des Mathématiques, 7(2), 5-31.

Durand-Guerrier, V., Boero, P., Douek, N., Epp, S. \& Tanguay, D. (2012). Examining the Role of Logic in Teaching Proof. In G. Hanna \& M. De Villiers (Eds.), ICMI Study 19 Book: Proof and Proving in Mathematics Education (pp. 369389). Springer: New-York.

Ghedamsi, I. (2008). Enseignement du début de l'analyse réelle à l'entrée à l'université, Unpublished PhD Thesis. Université Bordeaux 2, France. 
González-Martín, A.S. (2006). La generalización de la integral definida desde las perspectivas numérica, gráfica y simbólica utilizando entornos informáticos. Problemas de enseñanza y de aprendizaje, PhD Thesis. Universidad de La Laguna, Spain.

González-Martín, A.S. \& Camacho, M. (2004). Legitimisation of the graphic register in problem solving at the undergraduate level. The case of the improper integral. In M. Johnsen Høines \& A. Berit Fuglestad (Eds.), Proceedings of the $28^{\text {th }}$ Conference of the International Group for the Psychology of Mathematics Education (vol.2, pp. 479-486), Bergen (Norway): PME.

González-Martín, A.S. \& Correia de Sá, C. (2008). Historical-epistemological dimension of the improper integral as a guide for new teaching practices. In E. Barbin, N. Stehlikova \& C. Tzanakis (Eds.), History and Epistemology in Mathematics Education: Proceedings of the $5^{\text {th }}$ European Summer University (ESU-5) (pp. 211-223). Prague: Vydayatelsky Press.

Grønbæck, N., Misfeldt, M. \& Winsløw, C. (2009). Assessment and Contract-Like Relationships in Undergraduate Mathematics Education. In O. Skovsmose, Valero, P. \& Ravn, O. (Eds.), University Science and Mathematics Education in Transition (pp. 85-105). Springer Science + Business Media.

Gueudet, G., Buteau, C., Mesa, V., \& Misfeldt, M. (2014). Instrumental and documentational approaches: from technology use to documentation systems in university mathematics education. Research in Mathematics Education 16(2) [insert page numbers from this issue]

Haddad, S. (2012). L'enseignement de l'intégrale en classe terminale de l'enseignement tunisien. PhD Thesis. Université Virtuelle de Tunis et Université Paris 7 Denis Diderot.

Herbst, P. \& Kilpatrick, J. (1999). Pour lire Brousseau. For the Learning of Mathematics, 19(1), 3-10.

Hersant, M. \& Perrin-Glorian, M.-J. (2005). Characterization of an ordinary teaching practice with the help of the Theory of Didactic Situations. Educational Studies in Mathematics, 59, 113-151.

Kidron, I., Lenfant, A., Bikner-Ahsbahs, A., Artigue, M. \& Dreyfus, T. (2008). Toward networking three theoretical approaches: the case of social interactions. ZDM Mathematics Education, 40, 247-264. 
Krysinska, M. \& Schneider, M. (2002). Exploitation du concept de milieu pour analyser un enseignement relatif aux fonctions exponentielle et logarithme. In J.-L. Dorier, M. Artaud, M. Artigue, R. Berthelot \& R. Floris (Eds.), Actes de la $11^{e}$ Ecole d'Eté de didactique des mathématiques (pp. 187-196). Grenoble: La Pensée Sauvage.

Job, P. (2011). Étude du rapport à la notion de définition comme obstacle à l'acquisition du caractère lakatosien de la notion de limite par la méthodologie des situations fondamentales/adidactiques. PhD Thesis. Université de Liège, Belgium.

Legrand, M. (2001). Scientific debate in mathematics courses. In Holton, D. (Ed.), The Teaching and Learning of Mathematics at University Level: An ICMI study (pp. 127-135). Netherlands: Kluwer Academic Publishers.

Maracci, M., Cazes, C., Vandebrouck, F. \& Mariotti, M.A. (2013). Synergies between theoretical approaches to mathematics education with technology: A case study through a cross-analysis methodology. Educational Studies in Mathematics, 84(3), 461-485.

Margolinas, C. (2002). Situations, milieux, connaissances - Analyse de l'activité du professeur. In J.-L. Dorier, M. Artaud, M. Artigue, R. Berthelot \& R. Floris (Eds.), Actes de la $11^{e}$ Ecole d'Eté de didactique des mathématiques (pp. 141166). Grenoble: La Pensée Sauvage.

Maschietto, M. (2008). Graphic calculators and micro-straightness: analysis of a didactical engineering. International Journal of Computers for Mathematical Learning, 13, 207-230.

Mercier, A. (1995). Les effets de l'intervention enseignante dans les situations adidactiques. Les débats de didactique des mathématiques. Grenoble: La Pensée Sauvage Éditions.

Robert, A. (1998). Outils d'analyse des contenus mathématiques à enseigner au lycée et à l'université. Recherches en Didactique des Mathématiques, 8(2), 139-190.

Rogalski, M. (1998). Analyse épistémologique et didactique de connaissances à enseigner au lycée et à l'université : trois cours de la 9école d’Été de Didactique des mathématiques. Recherches en Didactique des Mathématiques, 18(2), 135-138.

Sackur, C. \& Maurel, M. (2002). La Presqu'île. Une introduction aux fonctions de deux variables en DEUG. In J.-L. Dorier, M. Artigue, R. Berthelot \& R. Floris (Eds.), 
A. S. González-Martín et al.

Actes de la $11^{e}$ Ecole d'Eté de didactique des mathématiques (pp. 167-176). Grenoble : La Pensée Sauvage.

Serrano, L., Bosch, M. \& Gascón, J. (2010). Fitting models to data: the mathematising step in the modelling process. In V. Durand-Guerrier, S. Soury-Lavergne \& F. Arzarello (Eds.), Proceedings of CERME6. Lyon, France.

Warfield, V. (2006). Invitation to Didactique. Seattle: University of Washington.

Winsløw, C., Barquero, B., De Vleeschouwer, M. \& Hardy, N. (2014). An institutional approach to university mathematics: from dual vector spaces to questioning the world. Research in Mathematics Education, 16(2), pp. [insert page numbers from this issue]. 